\title{
Struktur und Funktion der ostjakischen Fragesätze
}

\section{Die Struktur der ostjakischen Fragesätze}

Ausführlichere Spezialuntersuchungen über die ostjakische Syntax liegen bis jetzt nicht vor. ${ }^{1}$ Es empfiehlt sich deshalb, innerhalb des umfangreichen syntaktischen Gebietes ein Thema zu wählen, das leicht feststellbare Grenzen besitzt und somit exakt nach Aufbau und Bedeutung untersucht werden kann. Im vorliegenden Aufsatz wird bewusst auf Vergleiche mit den anderen ugrischen Sprachen ${ }^{2}$ oder den benachbarten Sprachen, z.B. dem Russischen, verzichtet.

Als Material dienen Exzerpte aus den verschiedenen Sammlungen von Volksdichtung, aus den Lehr- und Wörterbüchern des Ostjakischen, aus der Übersetzungsliteratur sowie aus den Schulbüchern für den Unterricht in den ostjakischen Schulen. Die Transkription ist nicht einheitlich, da sie jeweils den zitierten Quellen folgt. ${ }^{3}$ Doch spielt dies wie übrigens auch die Bezeichnung der Dialekte in einer syntaktischen Untersuchung wie der vorliegenden eine geringe Rolle; bei strukturmässigen

1 J. Fazekas veröffentlichte 1932 die Studie Az egyszerü mondat fajai az északi osztják nyelvben, worin die bis dahin erschienenen ostjakischen Sammlungen von Pápay als Materialgrundlage verwendet wurden. S. 29-34 wird der Fragesatz behandelt. Art und Zweck der Darstellung im Folgenden weichen von Fazekas' Schilderung ab. In dem 1937 erschienenen Werk Языки и письменность народов Cевера I. (Хантыйский [остяцкий] язык; 193-227) gibt W. Steinitz S. 222 einen Überblick über die ostjakische Syntax.

${ }^{2}$ Vgl. hierzu L. Knöpfler, A magyar és a vogul kérdömondat szórendje. Magyar Nyelvör 1936.

${ }^{3}$ Zwei Transkriptionszeichen in den Texten von Терёшкин sind durch die entspr. Zeichen der fiu.Umschrift ersetzt ( $\eta$ und $\chi$ ). 
Abweichungen wird auf den betreffenden Dialekt verwiesen, ansonsten werden alle im Druck zugänglichen ostjakischen Texte berücksichtigt. Wo es sich nicht um Zitate handelt, folge ich in der Transkription ostjakischer Wörter der Chrestomathie von W. Steinitz.

In diesem ersten Teil der Untersuchung wird, aufbauend auf der traditionellen Grammatik, die Struktur der ostjakischen Fragesätze dargelegt. Die semantische Seite wird hier nicht berücksichtigt, ihr ist Teil II gewidmet.

Ein Fragesatz unterscheidet sich von anderen Satzarten durch das Vorhandensein eines oder mehrerer Fragemorpheme. Bei der strukturellen Untersuchung des ostjakischen Fragesatzmaterials werden wir die folgenden Punkte zu unterscheiden haben:

1. Wortfolge als Fragemorphem

2. Interrogativpronomina, -adverbia und -partikel, die konkreten Fragemorpheme

3. Intonation als Fragemorphem

1. Wortfolge als Fragemorphem. Es gibt im Ostjakischen keine Fragesätze, die sich ausschliesslich durch die Wortstellung von Aussagesätzen unterscheiden. Der überwiegende Teil des Materials zeigt konkrete Fragemorpheme, und zwar gleichmässig verteilt auf die aus verschiedenen Zeiten stammenden, von unterschiedlichen Themen handelnden Texte. Der restliche Teil stammt hauptsächlich aus dem neueren ostjakischen Schrifttum, besonders aus der Übersetzungsliteratur und den Schulbüchern. Vorhanden ist der Typ der Fragesätze ohne konkrete Fragemorpheme jedoch auch schon in der Volksdichtung. Er muss also durch eine spezifische Intonation zum Fragesatz werden.

Hier ein Beispiel für die Gleichheit der Wortstellung in Frage und Aussage:

$\ddot{i} \cdot \gamma$ manəm tā $\cdot r n e \eta n u \cdot r k a \cdot s ̌ t a ~ m a \cdot n t a m$. Ich gehe, verheerende Rache für den Vater zu suchen (Stei V 272)

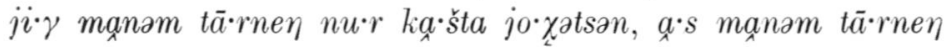
$n u \cdot r \quad k a \cdot s ̌ t a j o \cdot \chi z$ tsan? Bist du gekommen, um verheerende 
Rache für den Vater zu suchen, bist du gekommen, um verheerende Rache für die Mutter zu suchen? (Stei V 275).

Die Feststellung, dass die Wortfolge im Fragesatz der im Aussagesatz entspricht, kann durch folgende Beobachtungen erweitert bzw. unterstützt werden:

a. abhängig vom Charakter des Dialoges, der direkten Rede, richten sich die meisten Interrogativsätze an die 2. Person, vorwiegend im Singular. Das Personalpronomen steht dann im Ostjakischen allgemein am Anfang des Satzes, z.В. Нанг кашен? Ты болен? (Чехов 28); Нанг пушкан тайтын? А ружьё у вас (!) есть? (Хв 282); năn ұul putna pansen? Ты рыбу в котел положил? (Русс Во 258).

Ist das Subjekt erfragt, steht das Personalpronomen vor dem Prädikat: Патрон нанг тайтын? Патроны есть у тебя? (Хв

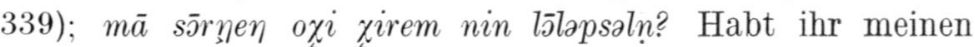
Goldgeldsack gestohlen? (Stei V 104).

Oder das Personalpronomen fehlt: mŏttija ujtantijtsan? bist du jemandem (einem Bären) begegnet? (Stei Chr 86); Ант паттын? Не боишься? (Хв 365); Утmа тангхаттын? Жить хочешь? (Хв 75); Ванттэн тыхыт? Видишь гнездо? (Хв 187); tìliš uda, zatt uda partten? Den Mond zu sehen, die Sonne zu sehen, befiehlst du? (Pa-Fu 204).

b. Vor dem "Aussagesatz" steht eine Anrede, Aufforderung zum Sprechen oder zum Antworten: na igi, mà xàl'mamna

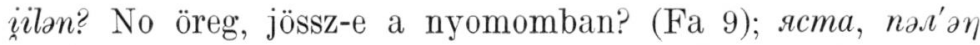
ики, нӥн мӥвә ёх киньтя вӧккәп васән? Скажи, батюшкаТуча, ты ли сильнее всех других? (Терё 139); Ма нангыт иньсистәм, тата хоят утл? Я тебя спрашиваю, есть тут люди? (Хв 359); ұanem, matti mə̄ś šūp at tajlan? Gevatter, hast du nicht irgendein kleines Märchen? (Stei V 65).

Charakteristisch für den Frage- wie auch für den Aussagesatz tritt die Personalform des Verbs in Endstellung. Die Stellung vor dem Prädikat ist dem gedanklich im Vordergrund stehenden Teil der Frage, d.h. dem Erfragten vorbehalten, an welcher Stelle offenbar jeder Satzteil stehen kann; in einem Fall gelangte zwar - offenbar durch Einfluss der russischen Vorlage - die finite Form des Verbs, das Prädikat, an den Anfang des Satzes. Beispiele: Нанг хосенны йингк утл? Около 
теб́я есть вода? (Хв 92); munat mettejat mededen, metta énda? Werdet ihr uns was geben oder nicht? (Pa-Fu 157); ̌men šat' ăntom? Hast du kein Mitleid mit deiner Frau? (Stei Chr

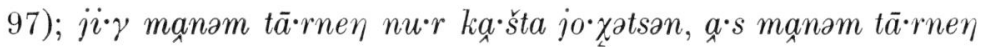

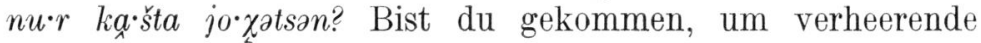
Rache für den Vater zu suchen, bist du gekommen, um verheerende Rache für die Mutter zu suchen? (Stei V 275).

Fragesätze ohne konkrete Fragemorpheme stellen nicht, wie u.a. bei Paul, Prinzipien der Sprachgeschichte S. 135 definiert, »den ganzen Satz» in Frage, sondern nur ein Glied von ihm. Das geht aus den folgenden wörtlichen Übersetzungen obenangeführter Beispiele anschaulich hervor:

Mein Goldgeldsack - ihr habt ihn gestohlen?

Gevatter, irgendein kleines Märchen - du hast es nicht?

2. Die konkreten Fragemorpheme. Der überwiegende Teil der ostjakischen Fragesätze enthält sog. konkrete Fragemorpheme, die aus den Pronominalstämmen $\chi 0^{-}, \chi u^{-}, m^{-}, m u-$ usw. gebildet sind oder Partikeln anderer Herkunft darstellen. Das erfragte Satzglied, meist unmittelbar vor dem Prädikat stehend, kann durch ein Fragepronomen ersetzt werden und wir erhalten ohne jegliche Änderung der Wortfolge einen Satz, der durch ein konkretes Fragemorphem gekennzeichnet ist. Dadurch ist erwiesen, dass auch der ostjakische Fragesatz mit einem Pronominalelement die gleiche Wortfolge wie der Aussagesatz besitzt.

Diese Gesetzmässigkeit ist eine in eine Richtung verlaufende Transformation ${ }^{1}$, deren Resultat die häufigste ostjakische Fragesatzstruktur zeigt und die in ihrer einen Grundform folgende Regel erhalten kann:

strukturelle Analyse: $\mathrm{S} \rightarrow \mathrm{NP}+\mathrm{VP} \quad \mathrm{VP} \rightarrow \mathrm{N}_{1}+\mathrm{Adv}+\mathrm{V}$ strukturelle Veränderung ${ }_{1} \mathrm{~S} \rightarrow \chi$-NP $+\mathrm{VP}$ strukturelle Veränderung ${ }_{2} \mathrm{~S} \rightarrow \mathrm{NP}+m-\mathrm{N}+\mathrm{Adv}+\mathrm{V}$

1 im Sinne von Chomsky, Syntactic Structures und Gleason, An Introduction to Descriptive Linguistics ${ }^{2}$. - Den Buchstaben $m$ verwende ich für die $m$-Fragewörter des Ostjakischen, $\chi$ für die $\chi$-Fragewörter. 
strukturelle Veränderung ${ }_{3} \mathrm{~S} \rightarrow \mathrm{NP}+\mathrm{N}_{1}+\chi$-Adv $+\mathrm{V}$

Beispielsatz:

năn zul putna pansen? Hast du den Fisch in den Kessel getan?

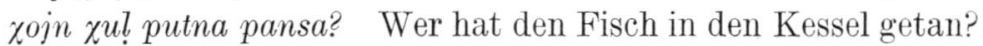
năn muj putna pansen? Was hast du in den Kessel getan?

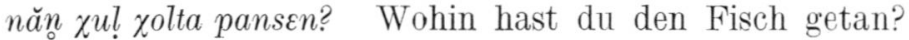

Oder:

strukturelle Analyse: $\mathrm{S} \rightarrow \mathrm{VP} \quad \mathrm{VP} \rightarrow \mathrm{Adv}+\mathrm{V}$

strukturelle Veränderung: $\mathrm{S} \rightarrow \chi-\mathrm{Adv}+\mathrm{V}$

Beispielsatz:

unta manzs? Ging er in den Wald?

zolta manzs? Wohin ging er?

Allerdings ist zu erwähnen, dass diese Transformation nicht nur für die Fragesätze charakteristisch ist, sondern ebenso für die anderen Satzarten gilt, d.h. wo ein bestimmtes Satzglied durch ein demonstratives, indefinites bzw. interrogatives Pronominalelement ersetzt wird.

Im folgenden werden die strukturellen Satztypen von Fragesätzen mit konkreten Fragemorphemen ungeachtet ihrer Bedeutung analysiert.

a. Interrogativpronomina

zoj 'wer'

Absoluter Gebrauch:

1. $\chi 0 j+$ finite Verbform

хой унта янгхыс? Кто ходил в лес? (Русс 3); xоi kitlem jāsinn tüta? Wen sende ich hin, die Botschaft zu bringen? (Ahlqv 5)

2. $\chi 0 j$ als nominales Prädikat

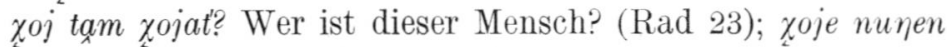
sat? Wer tut dir leid? (Pa-Fu 88)

3. $\chi 0 j+$ Kasusendung + finite Verbform

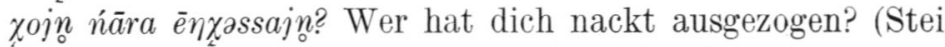

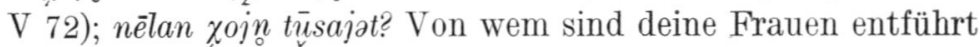
worden? (Stei V 94); хойны пальта ихытса? Кем повешено пальто? (Русс 49); Хойны нанг тунгытта унлтысыин? Кто же тебя учил читать? (Толстой 66); Тов хойны кирса? Кем запряжена лошадь? (Русс 102); Учитель хоя книга .мас? Кому учитель дал книгу? (Русс 48) 


\section{4. $\chi \circ j+$ Possessivsuffix}

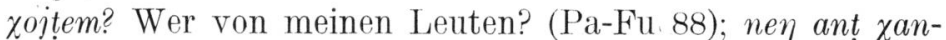
lați pā xojțen seltta partln? Wenn ihr nicht dorthin reicht, wen

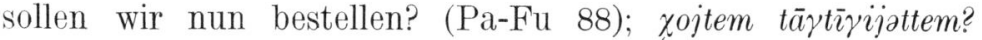
Wen erwarte ich? (Stei V II 111); xoidenenna jūxtäjen? Wer ist zu dir gekommen? (Pa-Fu 194).

Attributiver Gebrauch:

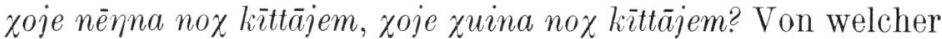
Frau, von welchem Mann werde ich aufgeweckt? (Pa-Fu 88)

муйсыьр, mи·j sir, mi, metta 'was für ein, welcher'

śätśa.śa, tam mu·j sir ńulamtan? Grossvater, was sind das für Wunden bei dir? ('das was für deine Wunden') (Stei V 271); муйсыр ёхан хонынгны нын куртәтн омысл? На какой реке стоит ваш посёлок? (Русс 4); муй сирны похие унтлыйтта numblc? Как стал учиться мальчик? (Хв 43). Im folgenden Beispiel sind die beiden Komponenten муй 'was' und cup 'Art, Gebrauch, Sitte' voneinander getrennt: Муй тохтынг па курынг сир вой нын унтэтнны утл? Какие птицы и звери водятся в вашем лесу? (Русс 4).

Im Surgut-Dialekt haben wir мӥв-урәи: Тэм ұатл' мӥв-урәи

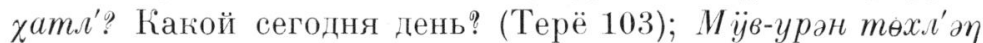
войхәт көрл'ал' тәх вӓрат? Какие птицы нарисованы? (Терё 115).

mi ai, mi ket tāidan-pa, mīja en jāstīden? Was für ein Wort, was für eine Rede hast du, weshalb sagst du es nicht? (Pa-Fu 89); tam metsir tau? Was ist das für ein Ross? (Pa-Fu 90); met-sir mō täidan? Was für Kinder wirst du haben? ( $\mathrm{Pa}-\mathrm{Fu}$ 90); met-sira jästeden? Wie wirst du sprechen? (Pa-Fu 135); қомпас мата нётл иса мар овыс пета памтыт? Какая стрелка в компасе всегда показывает на север? (Хв 157); metta ùdètteden? Wie geht es ihnen ('wie ihr Seiendes')? (Pa-Fu 213); mettap èva tãidan? Was für eine Tochter hast du? (Pa-Fu 89); met-omat no kīttam? Welche Möglichkeit habe ich aufzustehen? (Pa-Fu 90); pōtta-jinkèp jemèn sārat'-küttèba met-omat mendam? Wie kann ich bis zur Mitte des nicht zufrierenden heiligen Meeres gelangen? (Pa-Fu 135).

Der bei weitem häufigste Typus des ostjakischen Fragesatzes 4 - Finnisch-ugrische Forschungen 
enthält das Interrogativpronomen muj 'was' in seinen verschiedenen Formen und Entsprechungen in absoluter, aber auch attributiver Stellung. Absoluter Gebrauch:

1. $m u j+$ finite Verbform

muj wètsan? Was hast du gefangen? (Stei V 102); nan in muj tata wērlan? Was machst du denn hier? (Stei V 159); muịal käšmàn iăngal? Was suchend schreitet er? (Zsirai 83);

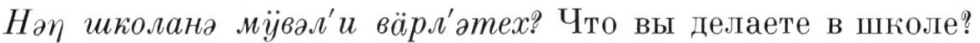
(Tepë 96); muj nin jéramman mośman patijn joxatsati? Warum seid ihr gekommen, was ist euch nötig ('was seid ihr in eurem nötig-gewordenen, entbehrten Ende gekommen')? (Stei V 156); Нанг муй ант вантэн, ма кумем антом? Некогда мне, разве не видишь? (Мамин-Сибиряк 66); medoje vāgitta? Was riefet ihr mich? (Pa-Fu 184).

2. $m u j+$ Possessivsuffix + finite Verbform

tutna medojem medem? Was werde ich dann geben? ( $\mathrm{Pa}-\mathrm{Fu}$ 122); mujlan pațlam kutn lēln? Was frisst du [da] im Finstern? (Stei V 135).

3. $m u j+$ Infinitiv

manem muj peeratti śi lowatñ ješalaslan? Was aufzuheben habt ihr mich in dieser Weise gerufen? (Stei V 71); luw tāklel mā in muj wèrti pitlam? Was soll ich nun chne ihn machen? (Stei $\mathrm{V}$ 156); śi ottšam xūrpi ot muj inśssti oš taj]? Was für einen Verstand hat [denn] dieses verrückte Wesen, dass man sie fragen könnte ('wäre es dieses verrückt gestaltige Ding', einen was-fragen Verstand hat es')? (Stei V 104).

4. muj als nominales Prädikat

sēmijenalan mujnan? Was sind deine zwei Äuglein? (Stei V 131).

5. $m u j+$ Nomen

. . . muil ātạm? . . talán rossz volna? (Pápay 23); . . muịal

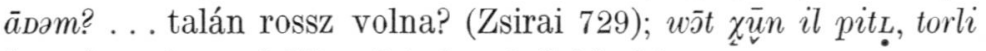
jāstati muj ātam? Was [ist denn] Schlechtes, genau zu sagen, wann der Wind aufhört? (Stei V 60). Diese Verbindung wird als stehende Redensart in der Bedeutung 'warum denn nicht'

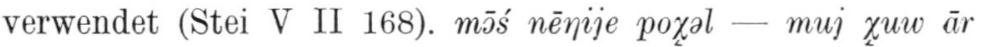
$\chi \bar{u}$ mōś $\chi \bar{u} \bar{e} n m e m a s ? ~ D e r$ Sohn der moś-Frau — wuchs der Liedermann, der Märchenmann etwa lange? (Stei V 88); w⿳亠丷厂 sōra muj ajLta il pitLo? Wird der Wind bald aufhören oder später? 
(Stei V 68); муй нане сэмндытан уннеын тамхатл? Отчего у тебя нынче такие большие глаза? (Толстой 19).

6. $m u j+$ Kasusendung + finite Verbform

Komitativendung: Мйвәл' инат айнә янтхал'? С чем играет девочка? (Терё 101); Lokativendung: па муйтымынны ий хорасыпнгын антомнгын? А в чём мы не одинаковы? (Хв 104); ёхан хуват муйны янгхтыт? На чём ездят по реке?

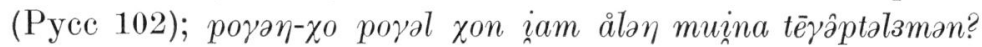
Womit füllen wir den Bauch vom Sohne des einen Sohn habenden Mannes? (Fokos 81); муйны kanycma nохлыт? Чем срезают капусту? (Русс 9); Lativendung: towwâ məowwala kkk manlan? Miksi menet sinne? (Paa Wb 1229); Өс нӥп мӥвл'әкћә

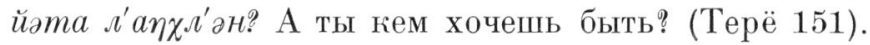

7. $m u j+$ Postposition (Nomen + Kasusendung $)+$ finite Verbform

muj ńāya ollen? Meddig alszod még? (Pápay 21); mui vōrna nè atmaś sāmtanna nōmistata? Warum denkt ihr so Arges in euren Herzen? (Matth. 9: 4, Ahlqv 55); муй отынгны пионеpыт nomblpmcыm? О чём рассказывали пионеры? (Хв 40).

8. $m u j+$ Verneinungsverb

$l u \eta^{2} n$ xul wēlluw muj antum? Werden wir im Sommer Fische

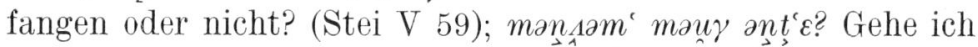

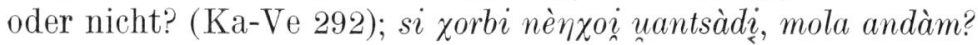
Ilyenforma embert láttatok-e, vagy nem? (Pápay 47).

Attributive Verwendung:

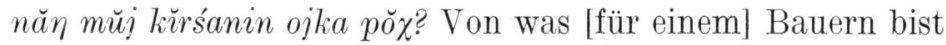
du der Sohn? (Stei Chr 92); śit ünta muj üno kan't? Was hast du für einen derartig grossen Zorn ('bis zu diesem was für ein grosser Zorn')? (Stei V 261).

In der gleichen Art wie die hier zitierten $m$-Fragepronomina

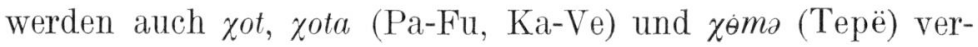
wendet.

Eine besondere Konstruktion erscheint in dem Text des Matthäusevangeliums, den Ahlqvist anführt. In anderen ostjakischen Texten ist mir eine derartige Konstruktion nicht begegnet: mui wird an die finite Verbform angehängt. Beispiele: pa neñ nemenna ār piś an versu-mui? Haben wir nicht in deinem Namen viele Taten getan? (Matth. 7: 22, Ahlqv 52); evilteta- 
mui, ma tami verta pusfem? Glaubt ihr, dass ich euch solches tun kann? (Matth. 9: 28, Ahlqv 57). In Paasonens Wörterbuch begegnet die gleiche Verwendung als Fragepartikel von

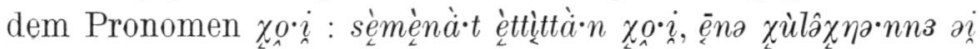

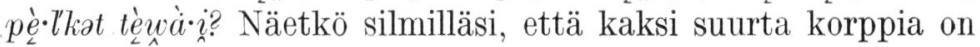
syönyt sen (kalan) toisen puolen? (Paa 475). — In seinem Artikel "Übereinstimmungen in der Syntax der finnischugrischen und türkischen Sprachen" (FUF 24) weist Fuchs S. 319-320 anhand von wotj., tscher., kas. und tschuw. Beispielen darauf hin, dass in der Entscheidungsfrage an das Prädikat oder den erfragten Satzteil oft eine Fragepartikel tritt, die ihrerseits häufig ein interrogatives Fürwort ist. ${ }^{1}$ Wir haben hier im Ostjakischen die gleiche Erscheinung.

$m u j+$ denominale Ableitung in der Bedeutung 'was für ein'

1. $m u j+-p i$

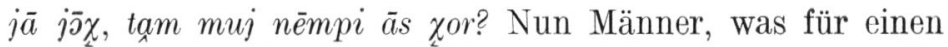
Namen hat diese (gerade) Ob-Strecke ('dies was-namige ObStrecke')? (Stei V 137); муй тампи ёханэтн паты? Какоедно у реки? (Русс 4).

2. $m u j+-\partial \eta$

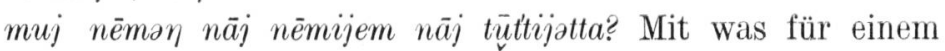
Namen ('mit meinem Namen einer was-namigen Schaitanin') werde ich Schaitanin genannt? (Stei V 371).

3. $m u j+-ә p$

муй хорасып тамхатл турыл? Какая сегодня погода? (Хв 257); нюрымм мув тунгын муй хорасып? Какова тундра летом? (Хв 5).

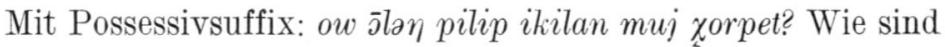
die Alten von der Art des owolen'er Philipp-Alten? (Stei V 67) muj in Verbindung mit einem zweiten konkreten Fragemorphem

1. muj m. Poss. + ұoti

Иван Иваныт, нанг муен хоты ийс? Иван Иваныч, что

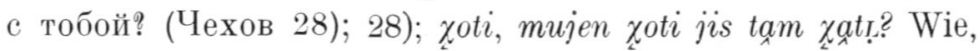
was ist denn heute mit dir los ('dein was wurde heute wie')?

${ }^{1}$ Beispiele hierzu s. auch Fokos-Fuchs, Die Rolle der Syntax in der Sprachverwandtschaft. Ural-Altaische Bibliothek 11. Wiesbaden 1962. S. $111-112$. 


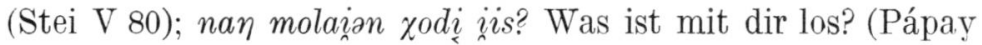
67, 68, 70). Auch dieser Ausdruck ist eine übliche Redensart (s. Stei V II 132).

\section{2. $x o t i+m u j$}

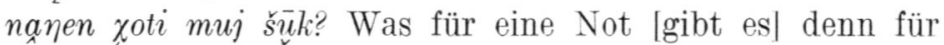

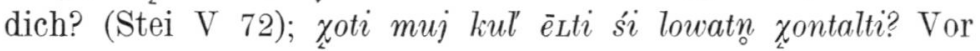
welchem Teufel flieht ihr denn so? (Stei V 78).

b. Interrogativadverbia ${ }^{1}$

zoti 'wie'

1. $\chi$ oti $^{+}$finite Verbform

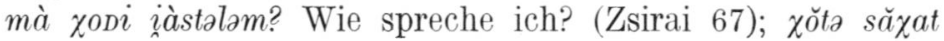
woj ara werta răxət? Wie gedeiht das Machen des Bärenliedes? (Stei Chr 86); nạ zoti weerlen luwel? Was machst du mit ihm?

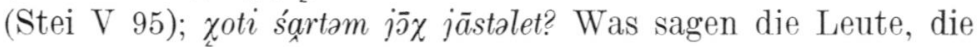
schamanisiert haben? (Stei V 68); xoté juvet? Von wo kamen sie? (Pa-Fu 95); xoti jêttšsasan muj antum? Bist du etwa fertig oder nicht? (Stei V 159). Mit verneintem Verb tritt auch kak auf: kak en tāidam? Wie soll ich es nicht haben? (Pa-Fu 136);

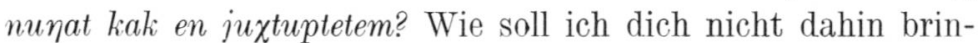
gen? (Pa-Fu 136); xoṭi anț uitlen? Hogy is nem tudsz? (Pápay 23); xodaś ant ulmīsen? Was hast du nicht geträumt (d.h. hast du etwas geträumt)? (Ahlqv 4); хотсат амп па хотынг яха утсангын? Как лебедь и собака жили вместе? (Хв 22).

xоmbl + Nomen

cum xоты атым вер? Нехорошо? (Мамин-Сибиряк 43); нанг хоты сакар петы самыне? Ты ведь любишь сахар? (Мамин Сибиряк 4).

$\chi \bar{u} n$ 'wann'

$\chi \bar{u} n+$ finite Verbform

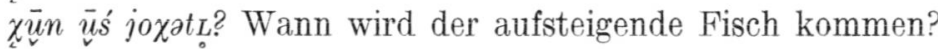

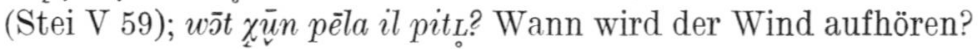
(Stei V 59); хунтә тәхәнә йәхил' әл'? Когда так бывает? (Терё 113)

$$
\begin{aligned}
& \text { xota 'wo' } \\
& \text { xota + finite Verbform }
\end{aligned}
$$

1 Vgl. E. Vértes, Beiträge zur Kenntnis der ostjakischen Pronominaladverbien I-III. AL XII 167-186, 255-271; XIII 15-33. 
тунгын нын хота усты? Где вы были летом? (Русс 3).

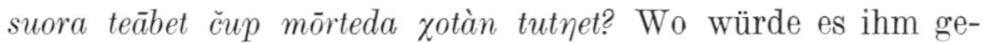
lingen, es schnell in 7 Stücke zu zerbrechen? (Pa-Fu 206);

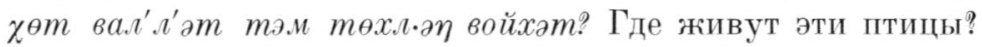
(Терё 115).

$$
\text { xoma }+ \text { Nomen }
$$

унтән хота? Где лес? (Русс 70); Ант утэн, хота ар воньсимот? Не знаешь-ли, где много ягод? (Хв 114).

zolta 'wohin'

xolta + finite Verbform

wōjlan xolta tüslan? Wohin hast du deine Tiere gebracht?

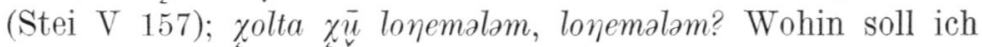
Mann mich verkriechen, verkriechen? (Stei V 177); xoj ünta eslam ot at tail, xolta noməs pont? Wer kein in den Wald gelassenes Ding (d.h. Rentier auf der Weide) besitzt - woran soll er denken? (Stei V 70, II 113).

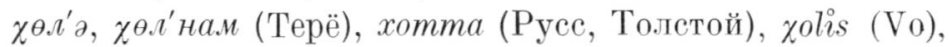
zotait'-pa (Pa-Fu) werden gleich konstruiert.

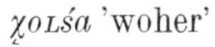

$\chi 0 L s ́ a+$ finite Verbform

¿ol'śa nạ jilan? Woher kommst du? (Rad 23)

$\chi \chi_{0 L} s a+$ Nominalform

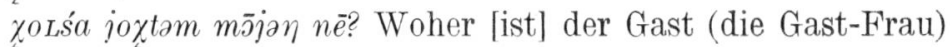
gekommen? (Stei V 87).

xотсясыт + Nomen

хотсясыт турымны хусыт? Откуда звёзды на небе? (Хв 36). $\chi \chi_{c} s^{\prime} a+$ Fragepronomen

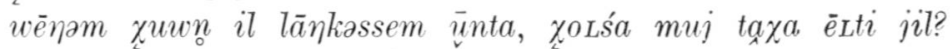
Meinen Schwiegersohn habe ich vor langem im Wald begraben, von wo (woher von welcher Stelle) soll er denn kommen? (Stei V 168).

muja 'warum', der Lativ von muj. Unter muj wurden bereits gleiche Konstruktionen mit der Stammform angegeben.

muja + finite Verbform

ăs-ǰ̆ amen-ĭmə mŭja tepattr̆jtten, mŭja šukatten? Warum betrügst du deine alte Tante, warum quälst du sie? (Stei Chr 102); muja tut at allan? Warum zündest du kein Feuer an? (Stei V 90); kärti $7 \bar{b} w$ muja wēLsaln? Warum habt ihr das eiserne 
Pferd getötet? (Stei V 160); мӥват Сеня атил'нат мәнл'әхән вөнтнам? Зачем Сеня и его отец идут в лес? (Терё 131).

In gleicher Stellung treten auch mija, mida, medoje, malai (Pa-Fu, Pápay) auf.

muj ar(at), kamən, muj kem 'wieviel'

Fragepronomen + finite Verbform

хуриленгкен муй ар тын тув таит? В корыте много ли корысти? (Пушкин 12); kaman wuli jēmà ńola tūtl'isti? Wieviel Rentiere habt ihr zum Heiligen Kap gebracht? (Stei V 68); kamn navrem skolan vəs? Сколько ребят в школе было? (Поп 61); ket skolaja kamn kniDa kitsb? В две школы сколько книг прислали? (Поп 61); округ муйкем район таит? Сколько районов имеет округ? (Хв 375).

Frageadverb + Nomen

муй арат тыв иса? Сколько же всех? (Хв 336); муйкем xот нын куртәтнны? Сколько домов в вашем посёлке? (Pyce 106).

$\chi \bar{u}$ in

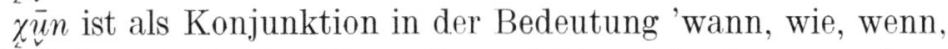
als' bekannt. In den Fragesätzen tritt es als Fragemorphem auf, in der Stellung gleicht es den Interrogativpronomina und -adverbia, erwartet jedoch keine Antwort, kein Ausfüllen der von ihm vertretenen Leerstelle. Es erscheint in folgenden Verbindungen:

1. $\chi \bar{u}$ n + finite Verbform

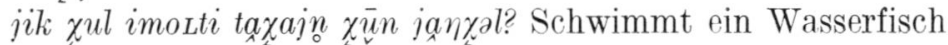
etwa [nur] an einer Stelle? (Stei V 103); Tам вер ма әеун версәм? Разве я это сделал? (Хв 312).

2. $\chi_{\mathrm{u}}^{\bar{u}}+\mathrm{n}+\mathrm{Nomen}$

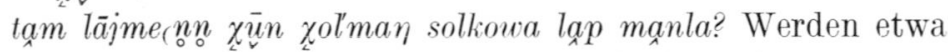
durch deine Axt da 30 Rubel gedeckt? (Stei V 74); ną pōtam

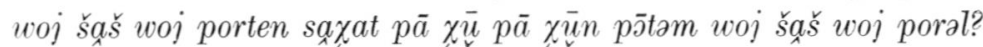
Während du [gutes] gefrorenes Fett [und] Rückenfett kaust, kauen andere Leute etwa auch gefrorenes Fett [und] Rückenfett? (Stei V 72).

3. Nomen $+\chi \bar{u}$ n

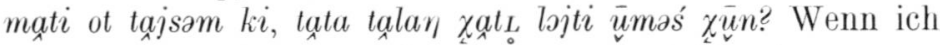
irgendwas hätte, [wäre es da] etwa interessant, hier den ganzen 
Tag zu stehen? (Stei V 73); ма ай хун? Разве я мальенкий?

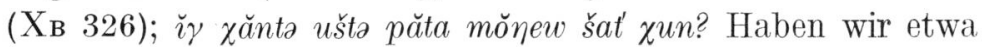
Mitleid mit einem sterbenden Ostjaken? (Stei Chr 82); иимыт хун тота похие? Мало ли там мальчики? (Хв 328).

c. Partikeln

ki 'wenn'

In den Einleitungen einer Frage oder in unvollständigen bzw. verkürzten Fragesätzen tritt $k i$ nachgestellt auf.

1. finite Verbform $+k i$

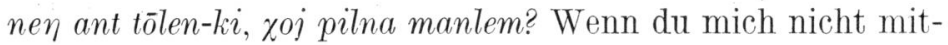
nimmst, mit wem sollte ich [dann] gehen? (Stei V II 119, Pápay 184); а маванкутл тәта тангхатылм ки? А если я постоянно есть хочу? (Мамин-Сибиряк 43).

2. Infinitiv $+\kappa u$

а ветта ки? А если убьют? (Хв 328).

3. Verneinungswort $+\kappa u$

а тыхтытны тангки антом ки? А если в гнезде белки нет? (Хв 87).

$$
\text { ada - ada 'entweder - oder, ob - ob' }
$$

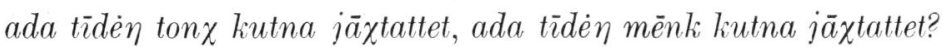
Steckt in ihnen der lebendige Geist oder steckt in ihnen der lebendige Teufel? ( $\mathrm{Pa}-\mathrm{Fu} 162)$; nè $\eta$ sat'meten at jit, man sat'mem at jit? (Ob) er euretwegen oder meinetwegen kommt? (Pa-Fu 160).

Kinm 'oder'

nָơn iàm k’âm ätam? Gut oder schlecht? (Ka-Ve 205)

pēla 'etwa, ob'

1. Nomen + pēla

sə̄ra pēla num tūram . . il arkaple Fällt der obere Himmel ... etwa bald herunter? (Stei V II 180); jena pēla vantsen? Sahst du ihn wirklich? (Ahlqv 4); zoj olin-pela potarlen? о комь ты говоришь? (Vo 69).

2. Verneinungswort + pēla

nènxoi ant-pèta ol? Talán csak nem ember van [a barlangjában]? (Faz 32).

3. Interrogativadverb + Verb und pēla malai kim-tajar'sèm pèta? Miért is akasztottam ki? (Faz 32). 
In den Aufzeichnungen von Karjalainen und Patkanow Fuchs kommen als konkrete Fragemorpheme auch zwei enklitisch verwendete Partikeln vor, nämlich - $a$ und $-l i$. In den Texten von Steinitz wie auch in der Übersetzungsliteratur (mit Ausnahme der religiösen Schriften) und den Schulbüchern begegnen sie nicht. Offenbar sind sie lediglich in den S- und O-Dialekten aufgezeichnet worden.

Bei Ka-Ve heisst es S. 99: "die Fragepartikel - $a$ wird an allerlei Wörter angehängt» (allerlei wohl für 'verschiedene Arten').

1. $-a$ an finiter Verbform

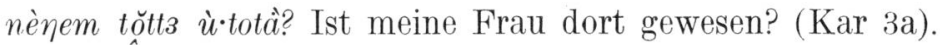

2. $-a$ an Nomen

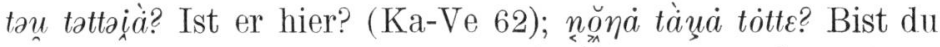
oder ist das Pferd dort? (Ka-Ve 99); jixpogem tu jatana? Ist mein Bruder zu Hause? (Pa-Fu 186).

3. $-a$ am Verneinungswort

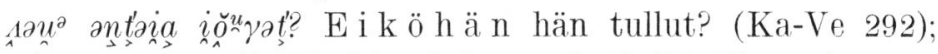

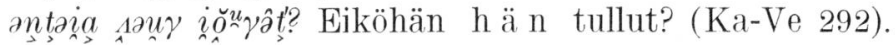

4. - $a$ und anderes Fragemorphem

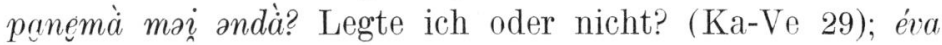
tu tātta-ta, metta en tāit? Hat er eine Tochter oder hat er keine?

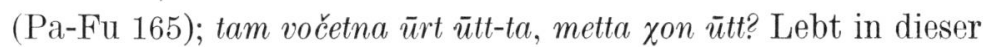
Stadt ein Held oder ein König? (Pa-Fu 165).

Partikel -li

1. $-l i$ an finiter Verbform

zunetena tut veda vāgat térmet-li, ent tèrmet-li? Das alles zu kaufen, reicht eurem König das Geld hin oder nicht? (Pa-Fu 157); munat ent partten-li nē $\eta$ èttītta? Gestattest du uns nicht, uns Frauen anzusehen? ( $\mathrm{Pa}-\mathrm{Fu} 167$ ); partasli tōrîm nenān ant teta matti jux-evilt? Hat Gott euch befohlen, von irgendeinem Baume nicht zu essen? (Ahlqv 28).

2. -li am Verneinungswort

tāidam cuka, punédivet ent-li tudeden? Ich habe eine Hofhündin, nehmet ihr sie nicht mit? (Pa-Fu 156); nineden pa $\chi$ ent-li most? Brauchet ihr nicht einen Sohn? (Pa-Fu 157); vèrdot metta ütt-ta, énda-li? Habe ich noch was zu schaffen oder nicht? (Pa-Fu 167).

3. $-7 i$ an Nomen 
nènxoîn-li, ali mola kul'-li tàm xàtna ol? ember-e vagy valami ördög van-e a házban? (Pápay 80).

Nachdem nun die einzelnen konkreten Fragemorpheme und die Konstruktionen, in denen sie auftreten, nach Typen unterschieden dargestellt wurden, lässt sich hinsichtlich ihrer Stellung und Struktur im Fragesatzgefüge folgendes sagen:

1. ausser als nominales Prädikat stehen die Fragepronomina und -adverben vor dem Satzteil bzw. Wort, das eine Leerstelle aufweist, die ergänzt werden soll oder vor einem Wort, das betont und hervorgehoben werden soll (bei Fragesätzen in anderer Funktion s. Teil II).

2. Bereits in relativ alten Sätzen kommt Anfangsstellung vor; häufiger ist sie in den modernen Lehrbüchern und der Übersetzungsliteratur. Als nominales Prädikat steht ein konkretes Fragemorphem am Schluss der Phrase.

3. Die Interrogativpronomina werden häufig mit Possessivsuffixen versehen.

4. In einem Fragesatz können zwei und mehr verschiedene konkrete Fragemorpheme auftreten. Nicht immer handelt es sich dann um kontrahierte Fragen wie im Fall (S. 53): Vor welchem Teufel flieht ihr denn so? (Welcher Teufel ist? Wie [warum] flieht ihr vor ihm?). Verstärkung durch Wiederholung liegt in dem Beispiel vor (S. 54): Meinen Schwiegersohn habe ich vor langem im Wald begraben, von wo (woher? von welcher Stelle?) soll er denn kommen?

Für den sog. mehrzieligen Fragesatz, der im Ungarischen so häufig ist und worin Simonyi eventuell slavischen Einfluss sehen will ${ }^{1}$ (vgl. ungar. kinek hol a helye? 'wessen Platz ist wo?') ist mir im ostjakischen Material kein Beleg begegnet.

5. Sogen. abhängige Fragesätze gibt es im Ostjakischen nicht, statt Hypotaxe haben wir Parataxe. Der logische Hauptsatz folgt dabei meist dem logischen Nebensatz (für das Wogulische kam Knöpfler S. 149 zum gleichen Ergebnis): was für ein Wort, was für eine Rede hast du, weshalb sagst du es nicht? (Pa-Fu 89).

1 S. Simonyi, Slavisches in der ungarischen syntax. FUF XII S. 23; s. auch H. Schuchardt, Der mehrzielige Frage- und Relativsatz. Graz 1893. 
6. Auch bei Fragesätzen mit konkreten Fragemorphemen unterscheidet sich die Wortfolge nicht von der in Aussagesätzen. Im folgenden bringe ich Beispiele gleich oder ähnlich konstruierter Aussagen und Fragen, die diese These beweisen.

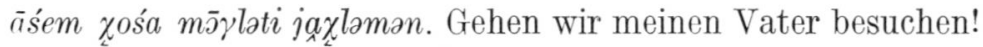
(Stei V 120); ма питзмнь Сеня хоси мойтыта манта кашасьтын? Хочешь поехать со мной в гости к Сене? (Хв 34). -

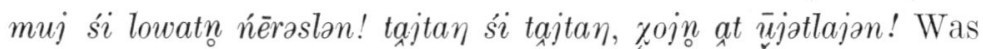
reizt du [mich] so sehr! Reich — ja reich [bist du], wer kennt

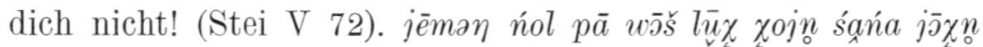
at üjatlajtn? Wer von den Synja-Bewohnern kennt nicht das

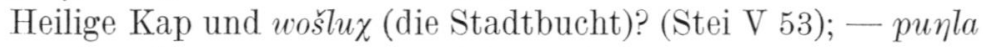
pārti muj ātam. Es wäre nicht schlecht, sie wegzuschicken.

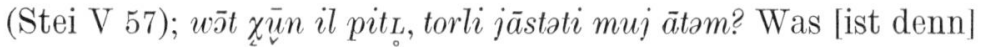
Schlechtes, genau zu sagen, wann der Wind aufhört? (Stei V 60).

Hier sei kurz ein Blick auf das Idg. gestattet. In seiner Syntax des einfachen Satzes im Indogermanischen (1925) sagt Brugmann (S. 222), dass die Wortstellung im Fragesatz in uridg. Zeit keine wesentlich andere gewesen sein kann als in den übrigen Satzarten. Interessant ist ferner die Tendenz im Nhd., mit der Frageform Du kommst morgen? pro Kommst du morgen? auf ursprünglich Älteres zurückzukommen.

3. Intonation als Fragemorphem. Mit welchen Mitteln der menschlichen Stimme wird der Fragesatz nun im Ostjakischen realisiert? Festgestellt wurde bereits, dass sich die Struktur der ostjakischen Fragen nicht von jener der Aussagen unterscheidet. Unabhängig vom Vorhandensein konkreter Fragemorpheme besitzt die Intonation in den ostjakischen Fragesätzen eine syntaktische Funktion. ${ }^{1}$ Eine Inversion gibt es nicht; durch Intonation wird eine Aussage in eine Frage transformiert. Im Zweifelsfall zeigt allein die Sprachmelodie, ob wir es mit einer

\footnotetext{
1 »Therefore it (intonation) has a decisive position in the hierarchical structure of utterances, for it can modify or even neutralize the semantic and/or the grammatical structure of utterances in a certain respect» (František Daneš, Sentence Intonation from a Functional Point of View. Word 16, 1. S. 54).
} 
Entscheidungs- oder Ergänzungsfrage zu tun haben oder ob eine artfremde Funktion des Fragesatzes vorliegt.

Mit der Intonation des Ostjakischen hat man sich m.W. wissenschaftlich nicht beschäftigt. Das Material, das darüber vorliegt, beschränkt sich auf Erwähnungen bei Fazekas (S. 30-31). Noch kürzer fasst sich Knöpfler (S. 98) hinsichtlich der wogulischen Fragesätze; im Anhang der Wogulischen Volksdichtung I-VI finden sich einige Intonationskurven. Ferner ist darauf hingewiesen worden, dass die Intonation im Ostjakischen und Wogulischen der im Ungarischen stark ähnele (über letztere s. A mai magyar nyelv rendszere II $504-517)$.

Im Rahmen des vorliegenden Aufsatzes möchte ich mich damit begnügen, nur das Grundsätzliche über die Satzmelodie der ostjakischen Fragesätze anzuführen. Einer späteren Untersuchung soll es überlassen bleiben, die Intonation im Ostjakischen als geschlossenes Thema zu behandeln, wobei auf die Toneinheiten (tone units) des Satzes mit ihren Kernsegmenten (nuclear segments) und dem Kernton (nuclear tone) sowie dem Hauptakzent (stress) eingegangen werden soll. ${ }^{1}$

In Entscheidungsfragen ohne konkretes Fragemorphem liegen Fragehochton und Hauptakzent auf dem erfragten Satzglied bzw. Wort:

1 Zum Inhalt der angeführten Begriffe s. z.B. K. L. Pike, The intonation of American English (Ann Arbor 1945) und R. Quirk,, A. P. Duckworth, J. Svartvik, J. P. L. Rusiecki and A. J. T. Colin, Studies in the correspondence of prosodic to grammatical features in English (London 1962). 
zàdàizm tùslàn.

Az asszonynénémet elhoztátok.

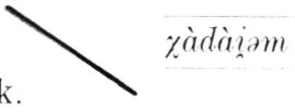

tùstàn

Frage

xàdàiram tùs_làn?

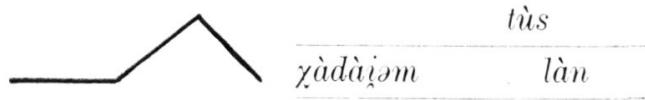

id.

Frage

xàdàizm tùslàn?
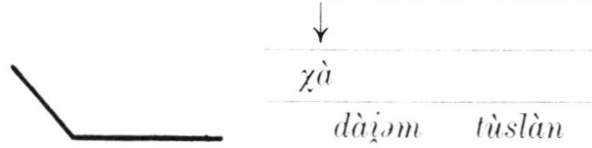

Az asszonỵnénémet hoztátok el:

Kombiniert mit einem konkreten Fragemorphem tritt die Intonation z.B. wie folgt auf: die Aussage mola inrèmamèn valamit elfelejtettél $\longrightarrow$ wird durch die Intonation transformiert in eine Entscheidungsfrage:

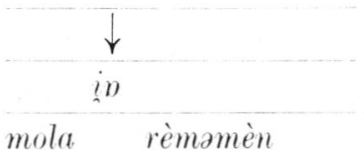

durch ᄂ in eine Ergänzungsfrage:

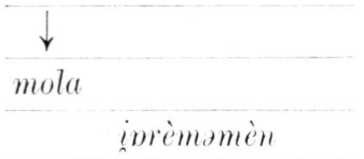

Für die Ergänzungsfrage gilt die Regel, dass die maximale Höhe und der Hauptakzent auf dem Fragewort liegen. 


\section{Die Funktion der ostjakischen Fragesätze}

Den Ausgangspunkt für die Einteilung muss hier die Antwort bilden. "Die Frage richtet sich in ihrer Gestaltung nach der Antwort, nimmt sie vorweg, soweit das möglich ist..1

Die Überprüfung des ostjakischen Materials ergibt, dass sich die folgenden Funktionsarten unterscheiden lassen:

1. Entscheidungsfragen
a. reine
b. mit Fragemorphem
c. disjunktive

2. Ergänzungsfragen

a. mit Interrogativpronomina

b. mit interrogativen Pronominaladverben

3. Unvollständige Fragesätze

4. Formelle Fragesätze in artfremder Funktion
a. Ausrufesatz
betonte Feststellung:
Ablehnung, Verneinung:
b. Wunschsatz

1. a. Die reinen Entscheidungsfragen, die also keinerlei konkretes Fragemorphem besitzen, bilden bei weitem die Minderheit im Material. Am seltensten treten sie in den älteren Aufzeichnungen, in der Folklore auf, relativ am häufigsten in den modernen Lehrbüchern und in der Übersetzungsliteratur. Auf Entscheidungsfragen wird positiv oder negativ mit der finiten Verbform geantwortet, z.B. Вуты ханнәхоя мосл? Мосл. Нужен человеку олень? - Нужен (Хв 38); Ант паттын? - Антом, ант паттыл. Не боишься? Нет, я не боюсь (Хв 365), oder aber durch Wiederholung des am An-

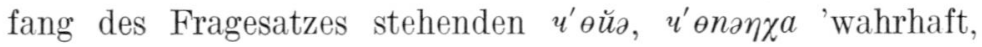
wirklich, правда-ли' (Surgut): Ч' өйә мйвә йәтат вӧкћәп васән

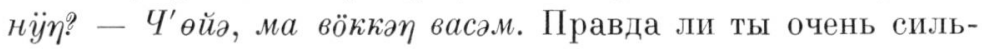
ный? Правда, я сильный (Терё 140) oder durch die bejahende

1 W. Porzig, Das Wunder der Sprache. 1950. S. 351. 
oder verneinende Wiederholung des erfragten Satzgliedes: Нане камен? - Камен (Чехов 28).

Jeder beliebige Satzteil der Entscheidungsfrage kann erfragt sein; innerhalb der Wortfolge sahen wir bereits die Tendenz, dass das erfragte Glied vor das Prädikat tritt. Erfragte Artergänzungen des Ortes, der Zeit und der Art und Weise stehen meist zu Beginn des Satzes. Für die Bedeutung der Wortfolge lassen sich die beiden folgenden Fragen anführen; die Fragepartikel - a tritt auch im unten dargestellten Material nicht an Nomina oder z.B. Personalpronomina, sondern an das Prädikat oder an die adverbiale Bestimmung:

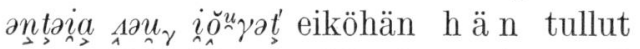

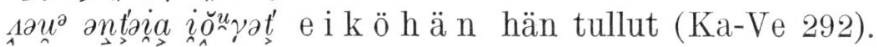

b. Die meisten Entscheidungsfragen haben konkrete Fragemorpheme, in der Hauptsache Partikeln: $-a$ und -li.

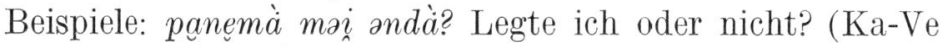
29); nènem tŏttz ù.totà? Ist meine Frau dort gewesen? (Karj 3 a);

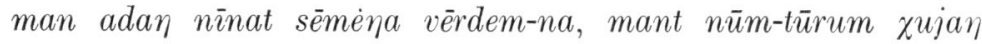
jina juxtupteta omat tāidan-a? Wenn ich euch sehend mache, bist du imstande, mich zu den Männergewässern der oberen Welt zu bringen? (Pa-Fu 191); zunetena t'ut veda vāgat tërmet-li, ent tèrmetli? Das alles zu kaufen, reicht eurem König das Geld

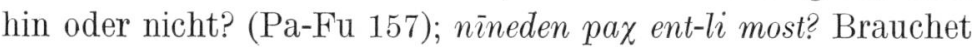
ihr nicht einen Sohn? (Pa-Fu 157); -li tritt auch an Personal-

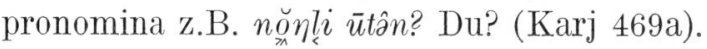

Beispiele für die Verwendung von Interrogativpronomina in Entscheidungsfragen: muj, metta in der Bedeutung 'oder'. Kennzeichnend ist, dass das pronominale Element grundsätzlich mit dem Verneinungswort auftritt: qoti jēttšasan muj antum? Bist du etwa fertig oder nicht? (Stei V 159); tav jisna jānxīdem tāidan metta ènda? Hast du ein längst zugerittenes Pferd oder nicht? (Pa-Fu 157); nă otmen tărməs mŭj ănta? Bist du noch müde (dauerte deine Müdigkeit oder nicht')?

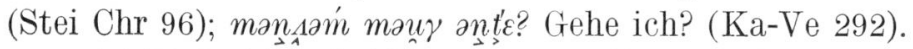

muj tritt in Entscheidungsfragen, allgemein in negativ gestellten, in der Bedeutung von 'denn, etwa, vielleicht' auf:

na्र·nen muj šăt'a эй нанг, Евра сэм, нанг муй порвой эвыт па ант паттын? 
Эй ты, Косой глаз, ты и волка не боишься? (Мамин-

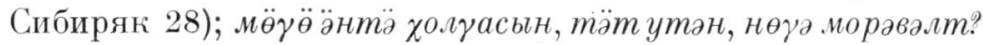
Разве (ты) не слышал, тут, в лесу, сучья трещат? (Терё B 107).

In der gleichen, aber positiven Funktion kommt xombl vor: Нанг хоты сакар петы самынг? Ты ведь любишь сахар? (Мамин-Сибиряк 4).

Auch modale Adverben kommen als Fragemorphem in Entscheidungsfragen vor: jena pēla vantsen? Sahst du ihn wirklich? (Ahlqv 4); metta-kes ei-t'u-ba nōrèmīvet ujin ńōga tēvīden? Hast du nicht in der Tat irgend einmal von dem Gestelle fettes Fleisch gegessen? (Pa-Fu 156).

c. Disjunktive Fragen treten relativ häufig auf, mitunter in

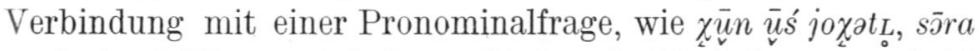
muj äjLta? Wann wird der aufsteigende Fisch kommen, bald oder später? (Stei V 59). Oder es handelt sich ursprünglich um zwei antithetische Entscheidungsfragen mit den enklitischen Partikeln - a oder -li: nূŏ $\eta \dot{a}$ tàua tótte? Bist du oder ist das Pferd

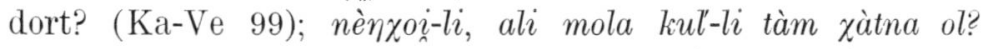
Ember-e vagy valami ördög van-e ebben a házban? (Pápay 80). Im Gegensatz zu Fazekas (S. 33) sehe ich in folgendem Satz, der übrigens einen recht oft vorkommenden Typus vertritt, keine disjunktive sondern eine Entscheidungsfrage mit pronominalem Element, die eine positive oder negative Antwort

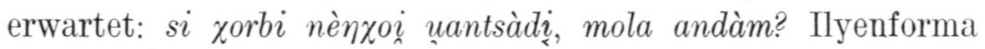
embert láttatok-e vagy nem? (Pápay 47).

2. a. Unter Ergänzungsfragen verstehen wir hier Fragesätze mit konkreten Fragemorphemen, die keine positive oder negative Antwort erhalten, sondern wo eine Leerstelle vorhanden ist und in der Antwort ausgefüllt wird. Gekennzeichnet sind diese Sätze durch attributiv oder absolut gebrauchte Interrogativpronomina oder (und) interrogative Pronominaladverben. Hinsichtlich ihrer Funktion werden die Ergänzungsfragen i.f. danach gruppiert, nach welchem syntaktischen Glied sie fragen.

zoi 'wer'

Subjekt: 
хой унта янгхыс? Кто ходил в лес? (Русс 3); ұоin mā lilna wērsajam? Von wem bin ich lebendig gemacht worden? (Stei V 167); хойны нанг тунгытта унлтысыин? Кто же тебя учил читать? (Толстой 66 ).

Objekt:

хоя ангкет мис әсым йингк мат? Кому мама даёт молоко? (Pycc 49); zojtem tāytizijattem? Wen erwarte ich? (Stei V II 111); тими ұојы мйл? Чья это шапка? (Терё В 70). muj 'was'

Es dient zunächst absolut als von Gegenständen und Tieren gebrauchtes Fragepronomen; es fragt nach dem nominalen

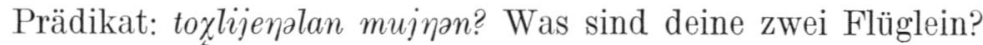
(Stei V 132), nach dem Subjekt: муй тувет мосыс? Что ему нужно было? (Чехов 26); nach dem Objekt: na· $\eta$ taxre nna muj we'rtam? Was mach ich mit deinem Panzer? (Stei V 274); мӥbал'и өяхтәх кешка? Кого увидела кошка? (Терё 125);

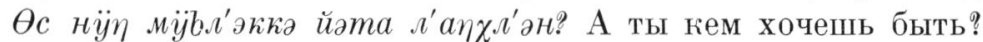
(Терё 151); Сорни турым, муй верта? Ђоже мой, что же делать? (Чехов 31).

In dieser Stellung wird muj auch in der Bedeutung 'warum' gebraucht: nạ in muj l'oxətiln? Was wäschst du dich nun? (Stei V 157); medoje vāgitta? Was riefet ihr mich? (Pa-Fu 184); муй нанг сэмнгытан уннгын тамхатл? Отчего у тебя нынче такие большие глаза? (Толстой 19).

Es fragt weiter nach einer adverbiellen Bestimmung des Ortes: мӥвә тахии нӥп мӓс йәүк вәл'ән? Откуда ты берёшь молоко? (Терё 121); мёвәл'ии пөм ӓнмәл? Из чего трава выходит? (Терё 121), der Art und Weise: муйны тыєе ёx йитыт? На чём они едут домой? (Русс 59); ланпӧүк мӥбёликӓ

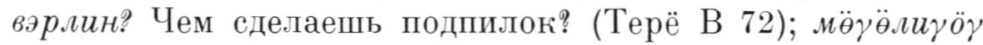
вэрмӓн кӧчеу? Из чего сделан нож? (Терё В 72).

Im attributiven Gebrauch steht muj vor dem Nomen, auf das es sich bezieht: manam muj jam wèritisn? Was hast du mir

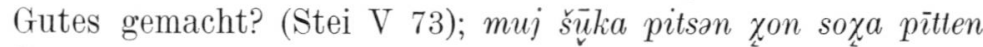
unta? In was für eine Not bist du geraten, dass du auf dem Bauch liegst? (Stei V 292).

Hierher gehört auch die Verwendung von muj vor denomi-

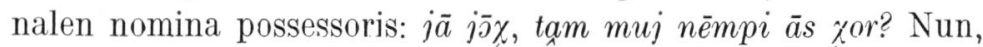
5 - Finnisch-ugrische Forschungen 
Männer, was für einen Namen hat diese (gerade) Obstrecke? (Stei V 137).

Die Fragepronomina in der Bedeutung 'was für ein, welcher' sind Ableitungen bzw. Weiterbildungen vom Fragestamm $m$-, z.B. муйсир, metsir, мӥв-урән, mettap, mett-ìda, мӓли usw.

Beispiele für absoluten Gebrauch: mett-ìda tutnet? Wie soll es geschehen? (Pa-Fu 135), муй сирны там вер тывыс - тув хотты томтыс? Как это могло случиться, что она заблудилась? (Чехов 3); für attributive Verwendung: tam metsir tau? Was ist das für ein Pferd? (Pa-Fu 90); nа муйсыр предмет утл нын классэтнны? Какие предметы есть ещё в классе? (Pyce 52).

b. Die ostjakischen fragenden Pronominaladverben sind in

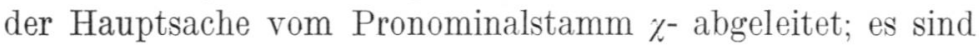
dies die Adverben in der Bedeutung 'wo', 'woher', 'wohin', 'wann', 'wie'. Vom m-Stamm sind 'warum' und 'wieviel' gebildet.

Xota 'wo' fragt nur nach der Lageangabe: тунгын нын хота yсты? Где вы были летом? (Русс 3); әпыл ос ұотәұы? А где мой отец? (Терё В 122).

xolta 'wohin' erwartet die Richtungsangabe: nājnalan

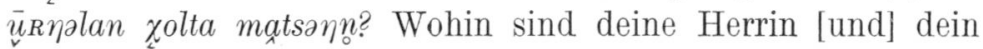
Herr gegangen? (Stei V 140). In den fiu. Sprachen werden eine Reihe von Verben anders konstruiert, erhalten ein anderes Präpositionalobjekt als in den idg. Sprachen. Hierher gehört besonders die Verwendung des Wohin-Kasus anstelle des idg. Wo-Kasus. ${ }^{1}$ Im Zusammenhang damit verdienen die folgenden Fälle Beachtung: zolta si $i$ lowatn aktaślati? Wohin versammelt ihr euch alle Mann? (Stei V 62); xolta taxərlisn tala zatt? Wo hast du den ganzen Tag gesteckt? (Stei V 128);

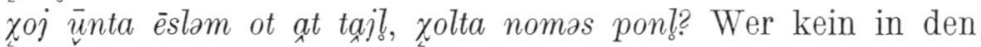
Wald gelassenes Ding besitzt, woran soll er denken? (Stei Vo 70).

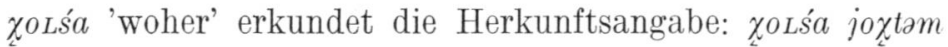
mōja n’e? Woher [ist] der Gast gekommen? (Stei V 87) oder den Grund: мё ұол' ульц. я почем знаю? (Терё В 147). Im

1 S. näher mit Beispielen z.B. L. Hakulinen, Handbuch der finnischen Sprache II 1960 S. 223 f. und Fokos-Fuchs a.a.O. S. 85 f. 
Ostjakischen wird gefragt: W o h e r sollen wir dich finden?

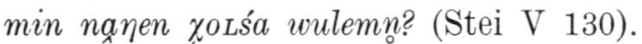

Bei Patkanow-Fuchs finden sich auch Beispiele (S. 95), nach denen zot', zote 'von wo, woher' offenbar instrumentale

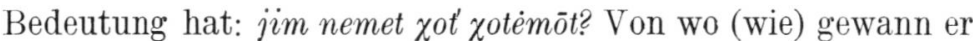
sich seinen schönen Namen?; man vegem qot'e vedesen? Woran werdet ihr meine Kraft erkennen?

$\chi \bar{u}$ ' 'wann' ist das zeitliche interrogative Pronominaladverb:

хун отынгмитпятилетка отынгтыйтыс? Когда началась первая пятилетка? (Хв 352).

zoti 'wie' fragt nach der Artergänzung:

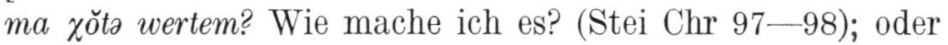

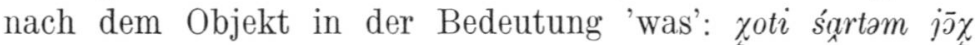
jāstəlat? Was sagen die Leute, die schamanisiert haben? (Stei V 68). Der Grund wird im folgenden Beispiel erfragt: $\chi$ oț ant uitlen? Hogy is nem tudsz? (Pápay 23).

muja 'warum' kommt in kausaler und finaler Verwendung.

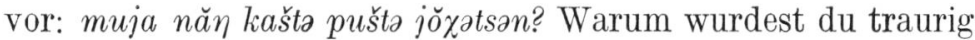
betrübt? (Stei Chr 86); pošxem muja šukatsen? Warum hast du mein Ei zerbrochen? (Stei V 167); Муя нанген тохтынг войле? На что тебе птички? (Толстой 49); a $ү k a$ ne, a a kka ne, tam xir soxijen muja wêrlem? Gevatterin, Gevatterin, was mach ('warum nehme') ich mit deinem Säckchen? (Stei V 84); towwô maowwalə.kka manlan? Miksi menet sinne? (Paa 1229); нявремыт муя мансыт? За чем пошли дети? (Русс 58).

kaman 'wieviel'

Meist steht das Satzglied, das eine Anzahlergänzung ver-

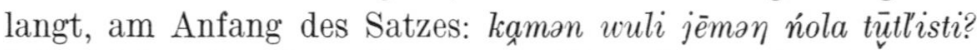
Wieviel Rentiere habt ihr zum Heiligen Kap gebracht? (Stei V 68).

3. Unvollständige Fragesätze. In der Übersetzungsliteratur und in den Lehrbüchern gibt es Fragesätze, bei denen praktisch der eigentliche Frageteil fehlt; er lässt sich ergänzen durch 'was ist (geschieht) dann?' Gemeinsam für diese Sätze ist die Verwendung der Konjunktion $к u$ 'wenn'. Beispiele: a ma ванкутл тәта тангхатым ки? А если я постоянно есть хочу? (Мамин-Сибиряк 43); а ветта ки? А если убьют? (Хв 328); 
A тыхтытны тангки антом ки? А если в гнезде белки нет?

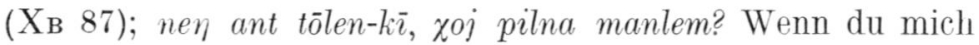
nicht mitnimmst, mit wem sollte ich [dann] gehen? (Stei V II 119 [Pápay 184]).

Dagegen werden unvollständige Fragesätze z.B. in einem russischen Original sonst stets als vollständiger Satz ins Ostjakische übersetzt, z.B. Нехорошо? - Cит хоты атым вер? (Мамин-Сибиряк 43).

4. Formelle Fragesätze in artfremder Funktion. In diesem Kapitel werden Fragen behandelt, die keine Antwort erwarten und gemeinhin als rhetorische Fragen bezeichnet werden. Sie lassen sich jedoch hinsichtlich ihrer Funktion bestimmten anderen Satzarten zuordnen und zeigen ferner Regelmässigkeiten in der Verwendung gewisser Pronominalelemente, die sonst auch als Fragemorphem gelten. Strukturell unterscheiden sie sich nicht von den eigentlichen Fragesätzen.

a. Eine ganze Reihe von Fragesätzen hat die Aufgabe eines Ausrufesatzes. Es handelt sich um Äusserungen, die in Form einer Frage entweder eine betonte Feststellung oder aber eine Verneinung, Ablehnung zum Ausdruck bringen. Beispiele zu

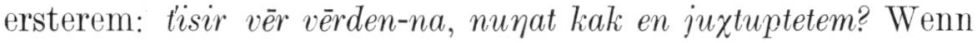
du eine solche Tat vollführst, wie sollte ich dich nicht dahin bringen? (Pa-Fu 168); pa neń nemenna kul'et xannēxojet-elta kim an vošatsu-mui? Haben wir nicht in deinem Namen Teufel

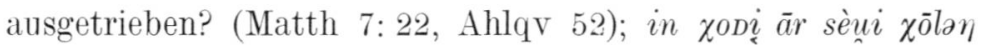

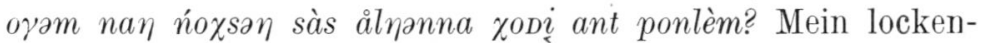
reiches Haupt, wie soll ich es nicht auf dein zobelfellbedecktes

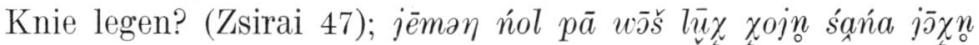
at ujatlajtn? Wer von den Synja-Bewohnern kennt nicht das Heilige Kap und wөšlu (die Stadtbucht)? (Stei V 53); нанг муй ант вантэн, ма кумем антом? Некогда мне, разве не видишь? (Мамин-Сибиряк 66). xodaś ant ulmisen? - jena ulmisem. Was hast du nicht geträumt (d.h. hast du etwas geträumt)? - Ich habe geträumt. (Ahlqv 4).

Charakteristisch für diese Art von Fragesätzen ist das in der Frage verneinte Prädikat. Diese Sätze haben die gleiche Funktion wie positive Ausrufesätze, eingeleitet etwa durch Adverben 
wie 'natürlich, selbstverständlich'. Der Beispielsatz aus der Volksdichtung von Steinitz löst im Hörer die gleiche Vorstellung aus wie z.B. der Ausruf: Natürlich kennt ein jeder Synja-Bewohner das Heilige Kap und die Stadtbucht! - Nach Havers (Handbuch der Syntax S. 190) zeigt übrigens das "unlogische» 'nicht' in Fragen dieser Art die soziale Rücksichtnahme des Sprechenden.

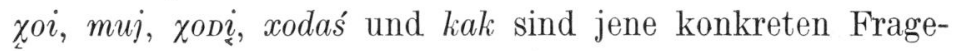
morpheme, die in diesen Fragen auftreten.

Beispiele für Fragesätze in der Funktion eines verneinenden

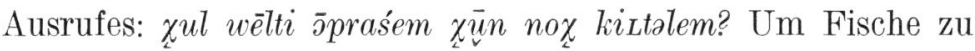
fangen, soll ich etwa meinen Grossvater [aus dem Grabe]

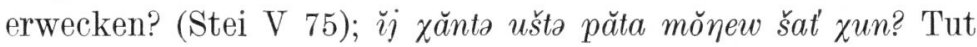
es uns um einen sterbenden Ostjaken etwa leid? (Stei Chr 82); üt wāj imoLti taxajan xūn janxal? Geht ein Waldtier etwa

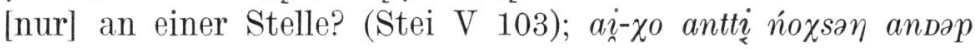
pà zun antlam? Wie könnte ich wieder einen ein Kind (eigtl. einen Kleinen) umgürtenden Zobelfellgürtel umgürten? (Fokos

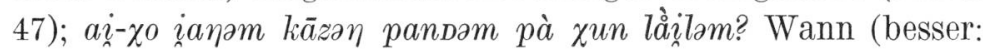
wie) stelle ich mich wieder auf den von einem Knaben (eigtl. kleinen Mann) gegangenen fröhlichen Weg? (Fokos 63); uимыт хун тота nохие? Мало ли там мальчики? (Хв 328).

Der überwiegende Teil der Fragen mit der Funktion eines ablehnenden Ausrufes enthält xun. Die beiden obigen Beispiele entsprechen genau z.B. den Sätzen: Nein, ein Waldtier geht an vielen Stellen! Hier sind aber viel Jungen!

Eine weitere Untergruppe enthält den Ausdruck muj ätam (und dessen Entsprechungen) 'was [ist denn] Schlechtes [dabei]':

iăxtempà muĩñl āDam? Wäre mein Gehen vielleicht schlecht? (Zsirai 19); tam jor kuri jiten pā toyall êtltațen muil ātam? Ezt az erős lábizmodot oda vinned talán rossz volna? (Pápay 23).

In den folgenden Belegen ist ebenfalls ein $m$-Fragewort ent-

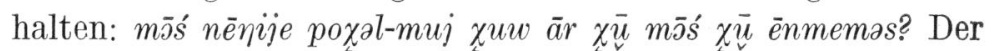
Sohn der moś-Frau — wuchs der Liedermann, der Märchenmann etwa lange? (Stei V 88); man ädèt-saǵa metta vīnā jāntt'em? Wie werde ich allein vom Weine kosten? (Pa-Fu 135).

b. Mitunter drücken Fragesätze auch einen Wunsch oder 


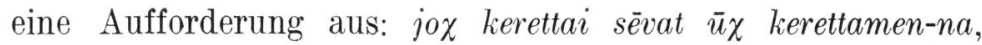
metta énda? Wird es uns gelingen, mit unseren bezopften Häuptern heimzukehren oder nicht? ( $\mathrm{Pa}-\mathrm{Fu}$ 165), d.h. möge es uns gelingen, hoffentlich gelingt es uns.

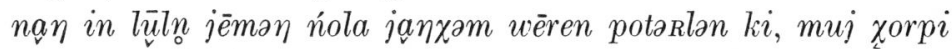
pēla? Wenn du jetzt von deiner Fahrt zum Heiligen Kap erzählen würdest, wie wäre das ('wie-gestaltig denn')? (Stei V 65). Die Reaktion auf diese "Frage" bzw. höfliche Aufforderung ist, dass der Angeredete zu erzählen beginnt.

Unlösbar verbunden mit dem Problem des Fragesatzes ist das der Fragepronomina, ihrer Entstehung, ihrer Rolle im Satz. Oben wurde darauf hingewiesen, dass es im ostjakischen Material auffallend wenig Fragesätze ohne konkrete Fragemorpheme, speziell ohne fragepronominale Elemente gibt. Im Hinblick darauf, dass solche reinen Entscheidungsfragen hauptsächlich in der Übersetzungsliteratur und in den Schulbüchern auftreten, kann man diese Art der Fragesätze im Ostjakischen als sekundär bezeichnen.

Für die finnisch-ugrischen Sprachen ist des öfteren ${ }^{1}$ auf die heutige indefinite Verwendung des Interrogativpronomens hingewiesen worden, ein Problem, das für sich selbst behandelt zu werden verdiente. Ferner ist aufmerksam gemacht worden auf die Gleichheit der diversen Pronominalstämme überhaupt. Auch beim Vergleich der finnisch-ugrischen und indogermanischen Sprachen hat man schon von den Anfängen der Sprachvergleichung an auch die Fragepronomina herangezogen, s. dann bei Anderson, Studien zur Vergleichung (1879): "Noch frappanter als bei den persönlichen Fürwörtern ist die Ähnlichkeit der finnisch-ugrischen und indogermanischen Sprachen in bezug auf die demonstrativa, interrogativa und relativa" (S. 84). In seiner Itämerensuomalaisten kielten pronominioppia, weist H. Ojansuu S. 89 darauf hin, dass die ostseefinnischen und finnisch-ugrischen Pronominalstämme ziemlich genau in der gleichen Form auf indogermanischer Seite auftreten.

1 z.B. Setälä, Budenz, Fincziczky, Ojansuu und Hakulinen in ihren Werken; für das Finnische heute vgl. Penttilä, Suomen kielioppi 525: "Die indefinite Bedeutung bei einigen Vertretungen von Wortformen von kuka, mikä, miten, milloin ist oft leicht mundartlich.» 
Welche Schlussfolgerungen lassen sich nun auf Herkunft und Alter der ostjakischen Fragepronomina anhand ihrer Verwendung in den Frage- und Aussagesätzen ziehen? Am vorliegenden Material wurde die Beobachtung gemacht, dass es Ergänzungsfragen mit Pronomina gibt, die sowohl indefinit als auch interrogativ verwendet werden können. Nehmen wir die Feststellung hinzu, dass sich der ostjakische Entscheidungsund Ergänzungsfragesatz in der Wortfolge nicht vom Aussagesatz unterscheidet, ergibt sich, dass der Fragesatz mit Interrogativpronomen eine Aussage mit Frageintonation + pronominales Element (indef. $\rightarrow$ interr.) ist. Das soll an zwei Beispielen veranschaulicht werden: na in muj noməs tajlan? Was für einen Gedanken hast du jetzt? (Stei V 145)

1. Stufe Du hast jetzt irgendeinen Gedanken.

2. "Welchen Gedanken hast du jetzt?

3. " Hast du jetzt irgendeinen Gedanken?

Intonation oder absolut:

jō lan muj jāstalat? Was sagen deine Leute? (Stei V 60)

1. Stufe Deine Leute sagen etwas.

2. "Was sagen deine Leute?

3. " Sagen deine Leute etwas?

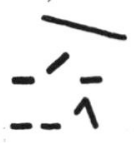

Abhängig vom Zusammenhang und von der Intonation können diese drei Stufen als Bedeutung des einen Satzes fungieren.

$\mathrm{Zu}$ der Feststellung, dass die indefinite Bedeutung des Pronominalstammes primär sein muss, kam bereits der englische Ägyptologe A. Gardiner in seinem Werk Speech and Language $^{2}$ (Oxford 1960, S. 308). ${ }^{1}$ Dass im Altägyptischen und sporadisch in Ausnahmen auch im Arabischen und in anderen semitischen Sprachen das interrogative Wort bzw. die interrogative Phrase nicht am Anfang des Satzes steht, gilt ihm als wichtigster Beweis für seine These. Am obigen Material ist

1 Angeschlossen haben sich ihm u.a. Meillet, Wegener, Kretschmer und Hirt in ihren Werken. Die gegenteilige Meinung wird u.a. von Fr. Meunier und Henri Frei vertreten, s. Frei, Interrogatif et Indéfini, Paris 1940. 
ausführlich gezeigt worden, dass die Anfangsstellung konkreter Fragemorpheme im Ostjakischen ursprünglich nicht vorkommt. - Delbrück sagt in seiner Vergleichenden Syntax I 521 zwar zum Problem der Primärität von Indefinit- oder Interrogativpronomen, dass diese Frage durch die Mittel einer historischen Untersuchung nicht zu lösen sei. Paul ist in seinen Prinzipien der Sprachgeschichte der Meinung, es gebe wohl kein Kriterium, woran sich erkennen liesse, welche dieser beiden Funktionen ursprünglich sei (S. 136). In diesem Zusammenhang verdienen die Arbeiten von Eduard Hermann ${ }^{1}$ über dieses Thema Beachtung. Nach ihm gilt für das Indogermanische wie für alle anderen Sprachen die Entwicklung: Demonstrativum - Interrogativum - Indefinitum. Er stützt sich dabei ausser auf etymologische Vergleiche 1. auf das Vorhandensein einer Wortfrage ohne Fragewort, besonders in der Kindersprache, doch auch in den Zeugnissen der Rede Erwachsener. Kinder lernen ja die Funktion von Fragesätzen und -wörtern sehr spät verstehen; sie fragen - und benutzen Frageintonation - is'n das? anstatt von 'was ist denn das?'. Für Wortfragen ohne Fragewort bei Erwachsenen führt Hermann die Einwortfragesätze bei Personalangaben an: (wie ist Ihr) Name? (wann sind Sie) geboren? usw. Dass 2. in der Ergänzungsfrage das Interrogativum ausserdem eine Fragepartikel der Entscheidungsfrage erhalten kann, gilt ihm als weiterer Beweis für seine Annahme. Für beide Sachverhalte lassen sich aber im ostjakischen Material keine Belege finden.

Eine Überlegung ist jedoch bei der mannigfachen Diskussion dieses Themas nicht angestellt worden. Wenn man, wie z.B. die Indogermanisten allgemein, annimmt, der Fragesatz sei "natürlich» später entstanden als der Aussage- und Aufforderungssatz, so sagt man damit eigentlich gleichzeitig, dass die interrogative Funktion des Pronominalstammes sekundär ist.

Ingrid Schellbach

1 E. Hermann, Problem der Frage. Nachrichten der Akademie der Wissenschaften in Göttingen. Philol.-Histor. Klasse. 1942. Ders., Herkunft unsrer Fragefürwörter. Sitzungsberichte der Bayerischen Akademie der Wissenschaften. Philos.-Histor. Abteilung. Jahrgang 1943. Heft 3. München. 


\section{Benutzte Abkürzungen der Materialveröffentlichungen}

Ahlqv = A. Ahlqvist, Über die Sprache der Nord-Ostjaken. Helsingfors 1880 .

Хв $=$ К. Ф. Хватай-Муха, Тунгытты книга. III. Учпедгиз 1951.

$\mathrm{Fa}=\mathrm{J}$. Fazekas, $\mathrm{Az}$ egyszerű mondat fajai az északi osztják nyelvben. Debrecen 1932.

Fokos = Osztják (chanti) hősénekek Reguly A. és Pápay J. hagyatéka III. kötet (1. füzet). Zsirai M. hagyatékából közzéteszi Fokos Dávid. Reguly Könyvtár 3. Budapest 1963.

Karj = K. F. Karjalainen, Ostjakisches Wörterbuch I-II. Bearbeitet und herausgegeben von Y. H. Toivonen. Helsinki 1948.

$\mathrm{Ka}-\mathrm{Ve}=$ Grammatikalische Aufzeichnungen aus ostjakischen Mundarten von K. F. Karjalainen. Bearbeitet und herausgegeben von E. Vértes. MSFOu 128. Helsinki 1964.

Мамин-Сибиряк = Д. Н. Мамин-Сибиряк, Потрыт. Учпедгиз 1948.

Paa $=$ H. Paasonens Ostjakisches Wörterbuch, nach den Dialekten an der Konda und am Jugan. Zusammengestellt, neu transskribiert und herausgegeben von Kai Donner. Helsinki 1926.

Pápay = J. Pápay, Osztják népköltési gyűjtemény. BudapestLeipzig 1905.

$\mathrm{Pa}-\mathrm{Fu}=\mathrm{S}$. Patkanow-D. R. Fuchs, Laut- und Formenlehre der südostjakischen Dialekte. Budapest 1911.

Поп = N. S. Popova, Arifmetika. I. Учпедгиз 1934.

Пушкин = А. С. Пушкин, Хут ветты хо па хутые отынгны моньсь. Учпедгиз 1948.

Rad $=$ K. Radanovics, Északi-osztják nyelvtan. Nyelvtudományi Értekezések 31. Budapest 1961.

Русс = Ю. Н. Русская -Н. И. Терёшкин, Ханты ясынг учебник (II). Учпедгиз 1951.

Русс Во = Вопросы финно-угорского языкознания. Ю. Н. Русская, О некоторых особенностях падежной системы приуральского говора хантыйского языка. 257-264. Москва 1962.

Stei Chr = Wolfgang Steinitz, Ostjakische Grammatik und Chrestomathie. Leipzig 1950.

Stei V = W. Steinitz, Ostjakische Volksdichtung und Erzählungen aus zwei Dialekten. 1. Teil Tartu 1939. 2. Teil Tartu-Stockholm 1941.

Терё = Н. И. Терёшкин, Букварь. Угпедгиз 1959.

Терё В = Н. И. Терёшкин, Очерки диалектов хантыйского языка. Часть первая. Ваховский диалект. Москва-Ленинград 1961.

Толстой = Л. Н. Толстой, Потрыт. Учпедгиз 1949. 
Чехов = А. П. Чехов, Каштанка. Учпедгиз 1952.

Vo = Budenz J., Osztják mondatok Vologodszki orosz-osztják szótárából. NyK 17 (1883), 161-189.

Zsirai = Osztják (chanti) hősénekek Reguly A. és Pápay J. hagyatéka II. kötet. Köszéteszi Zsirai Miklós. Reguly-Könyvtár 2. Budapest 1951. 